\title{
Transmission Mode Desorption Electrospray Ionization
}

\author{
Joseph E. Chipuk and Jennifer S. Brodbelt \\ Department of Chemistry and Biochemistry, University of Texas at Austin, Austin, Texas, USA
}

\begin{abstract}
$\mathrm{A}^{\circ}$ new $^{\circ}$ mode $^{\circ}$ of $^{\circ}$ operation $^{\circ}$ for $^{\circ}$ desorption $^{\circ}$ electrospray ${ }^{\circ}$ ionization $^{\circ}(\mathrm{DESI})^{\circ}$ analysis ${ }^{\circ}$ of $^{\circ}$ liquids ${ }^{\circ}$ or

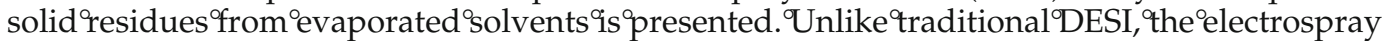

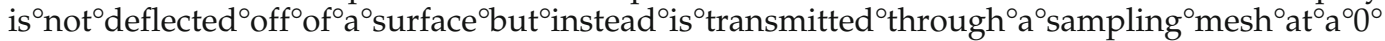
angle ${ }^{\circ}$ between ${ }^{\circ}$ the ${ }^{\circ}$ electrospray ${ }^{\circ}$ tip, ${ }^{\circ}$ sample ${ }^{\circ}$ mesh, ${ }^{\circ}$ and ${ }^{\circ}{ }^{\circ}$ apillary ${ }^{\circ}$ inlet ${ }^{\circ}{ }^{\circ} f^{\circ} a^{\circ}$ mass ${ }^{\circ}$ spectrometer.

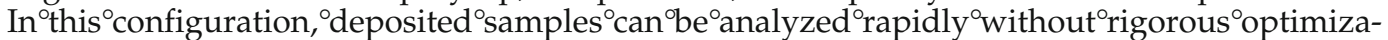
tion $^{\circ}{ }^{\circ} f^{\circ}$ spray $^{\circ}$ distances $^{\circ}$ or $^{\circ}$ angles ${ }^{\circ}$ and ${ }^{\circ}$ without $^{\circ}$ the ${ }^{\circ}$ preparation $^{\circ}$ time $^{\circ}$ associated $^{\circ}$ with $^{\circ}$ solvent evaporation. ${ }^{\circ}$ The $^{\circ}$ new $^{\circ}$ transmission $^{\circ}$ mode $^{\circ}$ desorption $^{\circ}$ electrospray $^{\circ}$ ionization $^{\circ}$ (TM-DESI)

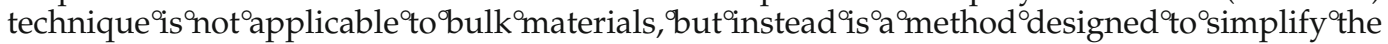
sample ${ }^{\circ}$ preparation ${ }^{\circ}$ process ${ }^{\circ}$ for ${ }^{\circ}$ liquid ${ }^{\circ}$ samples ${ }^{\circ}$ and ${ }^{\circ}$ sample ${ }^{\circ}$ extracts. ${ }^{\circ}$ The ${ }^{\circ}$ technique ${ }^{\circ}$ can ${ }^{\circ}$ reduce analysis ${ }^{\circ}$ time ${ }^{\circ}$ to ${ }^{\circ}$ seconds $^{\circ}$ while ${ }^{\circ}$ consuming ${ }^{\circ}$ only ${ }^{\circ}$ microliters ${ }^{\circ}$ of ${ }^{\circ}$ sample. ${ }^{\circ}$ The $^{\circ}$ results ${ }^{\circ}$ presented summarize ${ }^{\circ}$ the $e^{\circ}$ optimization ${ }^{\circ}$ of ${ }^{\circ}$ the ${ }^{\circ}$ technique, ${ }^{\circ}$ highlight ${ }^{\circ}$ key $^{\circ}{ }^{\circ}$ igures ${ }^{\circ}$ of ${ }^{\circ}$ merit ${ }^{\circ}$ for ${ }^{\circ}$ several ${ }^{\circ}$ model compounds, ${ }^{\circ}$ and ${ }^{\circ}$ illustrate $^{\circ}$ potential $^{\circ}$ applications ${ }^{\circ}$ to $^{\circ}$ high $^{\circ}$ throughput $^{\circ}$ screening ${ }^{\circ}$ of $^{\circ}$ liquid mixtures in ${ }^{\circ}$ ooth ${ }^{\circ}$ extraction ${ }^{\circ}$ solvents ${ }^{\circ}$ and ${ }^{\circ}$ biological ${ }^{\circ}$ matrices. ${ }^{\circ}$ ( $\left(\mathrm{J}^{\circ}\right.$ Am ${ }^{\circ}$ Soc $^{\circ}$ Mass $^{\circ}$ Spectrom 2008 , $\left.19,{ }^{\circ} 1612-1620\right)^{\circ}{ }^{\circ}{ }^{\circ} 2008^{\circ}$ American $^{\circ}$ Society ${ }^{\circ}$ for ${ }^{\circ}$ Mass ${ }^{\circ}$ Spectrometry
\end{abstract}

$\mathrm{D}$ esorption ${ }^{\circ}$ electrospray ${ }^{\circ}$ ionization $^{\circ}$ (DESI) ${ }^{\circ}[1-40]$, directªnalysis in real'time'(DART) 941$]$, ${ }^{\circ}$ desorption $^{\circ}$ atmospheric $^{\circ}$ pressure $^{\circ}$ chemical $^{\circ}$ ionization (DAPCI) $[12,22,42]^{\circ},{ }^{\circ}$ electrospray ${ }^{\circ}$ assisted $\%$ laser ${ }^{\circ}$ desorption $^{\circ}$ ionization $^{\circ}(\mathrm{ELDI})^{\circ}[43]$, atmospheric $^{\circ}$ solids $^{\circ}$ analysis probe $^{\circ}(\mathrm{ASAP})^{\circ}[44]^{\circ}$ and $^{\circ}$ flowing $^{\circ}$ afterglow ${ }^{\circ}$ atmospheric pressure ${ }^{\circ}$ glow $^{\circ}$ discharge $^{\circ}$ ionization $^{\circ}(\mathrm{FA}-\mathrm{APGD})^{\circ}[45,446]$ are $^{\circ}$ among $^{\circ}$ the ${ }^{\circ}$ recently ${ }^{\circ}$ developed $^{\circ}$ ambient $^{\circ}$ ionization techniques that ${ }^{\circ}$ have ${ }^{\circ}$ revolutionized ${ }^{\circ}$ mass $^{\circ}$ spectrometric analysis by ${ }^{\circ}$ facilitating ${ }^{\circ}$ direct $^{\circ}$ and ${ }^{\circ}$ rapid $^{\circ}$ analysis ${ }^{\circ}$ of both bulk ${ }^{\circ}$ materials ${ }^{\circ}$ (e.g., ${ }^{\circ}$ tissues, ${ }^{\circ}$ pharmaceuticals) ${ }^{\circ}{ }^{\circ}{ }^{\circ}{ }^{\circ}{ }^{\circ}$ samples deposited ${ }^{\circ}$ from ${ }^{\circ}{ }^{\circ}$ solution ${ }^{\circ}$ onto ${ }^{\circ} a^{\circ}$ sampling ${ }^{\circ}$ surface. In $^{\circ}$ the ${ }^{\circ}$ case $^{\circ}$ of ${ }^{\circ}$ DESI, $^{\circ}$ ions ${ }^{\circ}$ are $^{\circ}$ produced ${ }^{\circ}$ by $^{\circ}$ directing charged $^{\circ}$ solvent $^{\circ}$ droplets $^{\circ}$ from $^{\circ}$ an $^{\circ}$ electrospray ${ }^{\circ}$ source toward ${ }^{\circ} a^{\circ}$ sample.$^{\circ}$ Analyte ${ }^{\circ}{ }^{\circ}{ }^{\circ}$ the ${ }^{\circ}$ surface ${ }^{\circ}$ are ${ }^{\circ}$ ionized and $^{\circ}$ desorbed ${ }^{\circ}$ by $^{\circ}$ the ${ }^{\circ}$ incoming ${ }^{\circ}$ plume $^{\circ}$ before $^{\circ}$ mass analysis. ${ }^{\circ}$ DESI ${ }^{\circ}$ is $^{\circ}$ one ${ }^{\circ}$ of ${ }^{\circ}$ the ${ }^{\circ}$ more ${ }^{\circ}$ universal ${ }^{\circ}$ techniques since ${ }^{\circ} t^{\circ} \mathrm{can}^{\circ} \mathrm{be}^{\circ}$ used $^{\circ}$ to $^{\circ}$ analyze ${ }^{\circ}$ larger ${ }^{\circ}$ biomolecules ${ }^{\circ}$ and exploit ${ }^{\circ}$ reactive ${ }^{\circ}$ chemistry $^{\circ}$ via $^{\circ}$ alteration ${ }^{\circ}$ of $^{\circ}$ the ${ }^{\circ}$ solvent and $^{\circ}$ solvent ${ }^{\circ}$ additives ${ }^{\circ}[5] .{ }^{\circ}$ However, ${ }^{\circ} \mathrm{DESI}^{\circ}{ }^{\circ}$ equires ${ }^{\circ}$ optimization ${ }^{\circ}$ of ${ }^{\circ} a{ }^{\circ}$ array ${ }^{\circ}$ of ${ }^{\circ}$ experimental ${ }^{\circ}$ variables including $^{\circ} \mathrm{DESI}^{\circ}$ spray $^{\circ}$ solvent $^{\circ}{ }^{\circ}$ composition, ${ }^{\circ}$ desorption ${ }^{\circ}$ angle and $^{\circ}$ distances, ${ }^{\circ}$ sampling ${ }^{\circ}$ angle $^{\circ}$ and $^{\circ}$ distances $^{\circ}[5] .{ }^{\circ}$ Optimization ${ }^{\circ} s^{\circ}$ especially ${ }^{\circ}$ critical $^{\circ}{ }^{\circ}{ }^{\circ}$ the ${ }^{\circ}$ chemical $^{\circ}$ identity ${ }^{\circ}$ of the ${ }^{\circ}$ target ${ }^{\circ}$ analytes ${ }^{\circ}$ varies $^{\circ}[5]$.

Since ${ }^{\circ}$ its $^{\circ}$ discovery, ${ }^{\circ} \mathrm{DESI}^{\circ} \mathrm{has}^{\circ}{ }^{\circ}$ ound ${ }^{\circ} \mathrm{many}^{\circ}$ applications, ${ }^{\circ}$ including ${ }^{\circ}$ forensic ${ }^{\circ}$ analysis ${ }^{\circ}\left[5,{ }^{\circ} 14,{ }^{\circ} 25,{ }^{\circ} 29\right],{ }^{\circ}$ explosives $^{\circ}$ detection $\left[3,{ }^{\circ} 4,27\right]^{\circ},{ }^{\circ}$ chemical $^{\circ}$ warfare $^{\circ}$ agent $^{\circ}$ detection $^{\circ}\left[13,{ }^{\circ} 14,{ }^{\circ} 24,{ }^{\circ} 33\right],{ }^{\circ}$ imaging ${ }^{\circ}\left[12,{ }^{\circ} 26\right],{ }^{\circ}$ pharmaceutical

Address reprint requests to Dr. J. S. Brodbelt, Department of Chemistry and Biochemistry, 1 University Station A5300, University of Texas at Austin, Austin, ${ }^{\circ}{ }^{\circ}{ }^{\circ} 78712,{ }^{\circ} U S A .{ }^{\circ}$ E-mail: ${ }^{\circ}$ jbrodbelt@mail.utexas.edu analysis $^{\circ}\left[2,{ }^{\circ} 7-9,{ }^{\circ} 15,{ }^{\circ} 22,{ }^{\circ} 29,{ }^{\circ} 31,{ }^{\circ} 38\right]^{\circ}$, natural $^{\circ}$ product characterization $^{\circ}\left[5,{ }^{\circ} 6\right]^{\circ}$ polymer $^{\circ}$ analysis $^{\circ}\left[16,{ }^{\circ} 35\right]$, metabolomics ${ }^{\circ}\left[5,{ }^{\circ} 11,18,{ }^{\circ} 30\right],{ }^{\circ}$ proteomics ${ }^{\circ}\left[5,{ }^{\circ} 10,{ }^{\circ} 32\right],{ }^{\circ}$ and recent $^{\circ}$ progress ${ }^{\circ}$ tow $\operatorname{ard}^{\circ}$ glycomics $^{\circ}[40] .^{\circ}$ In $^{\circ}$ some $^{\circ}$ cases, samples ${ }^{\circ}$ are 9 ionized ${ }^{\circ}$ directly ${ }^{9}$ in their native ${ }^{\circ}$ environment (e.g., ${ }^{\circ}$ imaging, ${ }^{\circ}$ pharmaceutical ${ }^{\circ}$ analysis ${ }^{\circ}$ without $^{\circ}$ any pretreatment. ${ }^{\circ}$ However, ${ }^{\circ}$ in $^{\circ}$ many $^{\circ}$ others ${ }^{\circ}$ the ${ }^{\circ}$ sample ${ }^{\circ}$ is extracted ${ }^{\circ}$ or $^{\circ}$ otherwise ${ }^{\circ}$ prepared $^{\circ}$ in $^{\circ} a^{\circ}$ suitable ${ }^{\circ}$ solvent and $^{\circ}$ ultimately $^{\circ}$ deposited $^{\circ}$ onto $^{\circ} \mathrm{a}^{\circ}$ surface $^{\circ}$ (e.g., ${ }^{\circ}$ glass slide, ${ }^{\circ}$ paper, ${ }^{\circ}$ metal, ${ }^{\circ}$ plastic, ${ }^{\circ} \mathrm{TLC}^{\circ}$ plate).${ }^{\circ}{ }^{\circ}$ or ${ }^{\circ} \mathrm{DESI},{ }^{\circ}$ this sample ${ }^{\circ}$ preparation ${ }^{\circ}$ process ${ }^{\circ}$ often ${ }^{\circ}$ requires ${ }^{\circ}$ the ${ }^{\circ}$ complete evaporation ${ }^{\circ}$ of ${ }^{\circ}$ the ${ }^{\circ}$ solvent $^{\circ}$ before $^{\circ}$ analysis $^{\circ}$ since $^{\circ}$ the typical ${ }^{\circ}$ incident ${ }^{\circ}$ angle $^{\circ}$ of ${ }^{\circ}$ the ${ }^{\circ}$ electrospray $^{\circ}$ nebulizing plume ${ }^{\circ}$ tends $^{\circ}$ to $^{\circ}$ rapidly $^{\circ}$ erode $^{\circ}$ liquids $^{\circ}$ and ${ }^{\circ}$ dissolved solids $^{\circ}$ from ${ }^{\circ}$ the ${ }^{\circ}$ surface ${ }^{\circ}$ before ${ }^{\circ}$ they ${ }^{\circ}$ are $^{\circ}$ ionized. ${ }^{\circ}$ When the ${ }^{\circ}$ solvent ${ }^{\circ}$ is $^{\circ}$ highly $^{\circ}$ volatile ${ }^{\circ}$ (e.g., ${ }^{\circ}$ methanol), ${ }^{\circ}$ the ${ }^{\circ}$ evap-

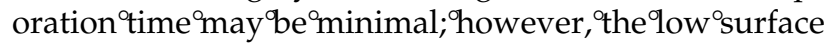
tension ${ }^{\circ}{ }^{\circ}{ }^{\circ}$ the ${ }^{\circ}$ solvent ${ }^{\circ}$ makes ${ }^{\circ}$ reproducible ${ }^{\circ}$ sample ${ }^{\circ}$ deposition ${ }^{\circ}$ more $^{\circ}$ challenging. ${ }^{\circ} \operatorname{In}^{\circ}$ cases $^{\circ}{ }^{\circ}$ where ${ }^{\circ}$ the ${ }^{\circ}$ solvent ${ }^{\circ}$ is less $^{\circ}{ }^{\circ}$ olatile ${ }^{\circ}$ (e.g. ${ }^{\circ}{ }^{\circ}$ water), ${ }^{\circ}$ the $^{\circ}{ }^{\circ}$ slow $^{\circ}{ }^{\circ}$ evaporation ${ }^{\circ}$ time ${ }^{\circ}$ of the ${ }^{\circ}$ solvent ${ }^{\circ}$ may $^{\circ}$ reduce ${ }^{\circ}$ sample ${ }^{\circ}$ throughput.

Historically, ${ }^{\circ}{ }^{\circ}$ major ${ }^{\circ}$ factor ${ }^{\circ}{ }^{\circ}{ }^{\circ}$ the ${ }^{\circ}$ successful ${ }^{\circ}$ application ${ }^{\circ}{ }^{\circ}$ DESI ${ }^{\circ}$ has been ${ }^{\circ}$ the ${ }^{\circ}$ tuning ${ }^{\circ}$ of ${ }^{\circ}$ the ${ }^{\circ}$ geometry ${ }^{\circ}$ of the experiment. ${ }^{\circ} \mathrm{The}^{\circ}$ numerous $^{\circ}{ }^{\circ}$ egrees $^{\circ}$ of $^{\circ}$ freedom ${ }^{\circ}$ associated ${ }^{\circ}{ }^{\prime}$ ith ${ }^{\circ}{ }^{\circ}$ freely ${ }^{\circ}$ adjustable ${ }^{\circ}$ sample ${ }^{\circ}$ stage ${ }^{\circ}$ and ${ }^{\circ}$ spray ${ }^{\circ}$ tip relative to a fixed capillary inlet allow incredible flexibility, but in doing so add inherent complexity. Key adjustable parameters, including incident and collection angles, sample height and spray heights, and plume impact to inlet distance are typically optimized, but often differ among sample types. Recent efforts have been aimed at simplifying the DESI experiment by fixing the geometric arrangement of the sample surface, 
spray tip, and capillary inlet [34]. In these studies, the dependence on angles and distances is minimized by enclosing the sampling surface in a small chamber and spraying the surface with both the spray tip and capillary held near $90^{\circ}$ to it. The ion cloud is created within the sample chamber and transferred into the mass spectrometer due to the pressure differential of the vacuum. In other work, solid-phase microextraction (SPME) fibers used to extract either vapors from the headspace of samples or analytes from solution have been inserted into an electrospray plume for DESI analysis [24, 39]. In these instances, the surface area was sufficiently small relative to the electrospray plume and ionization of adsorbed surface analytes occurred as the plume traveled around the fiber.

The present investigation reports an alternate method for simplifying the geometry dependence of DESI experiments that require sample deposition. In this method, the sample is not deposited onto a continuous solid surface but rather onto a sampling mesh. Instead of deflecting the electrospray plume off of the surface and into the mass spectrometer, the incident spray angle is reduced to $0^{\circ}$ and the spray is transmitted through the sample (Figure 1). This "transmissionmode" DESI technique allows for rapid analysis of both deposited residues and solutions without rigorous optimization of spray distances or angles and without the preparation time associated with solvent evaporation.

\section{Experimental}

\section{Materials}

Nicotine, cotinine, bradykinin, quercetin, apigenin, myricetin, and rhodamine 6G were purchased from Sigma Aldrich (St. Louis, MO). Neurotensin and Substance $\mathrm{P}$ were purchased from Bachem (Torrence, CA). All standards were used without further purification and prepared in high purity solvent (e.g., water, meth-

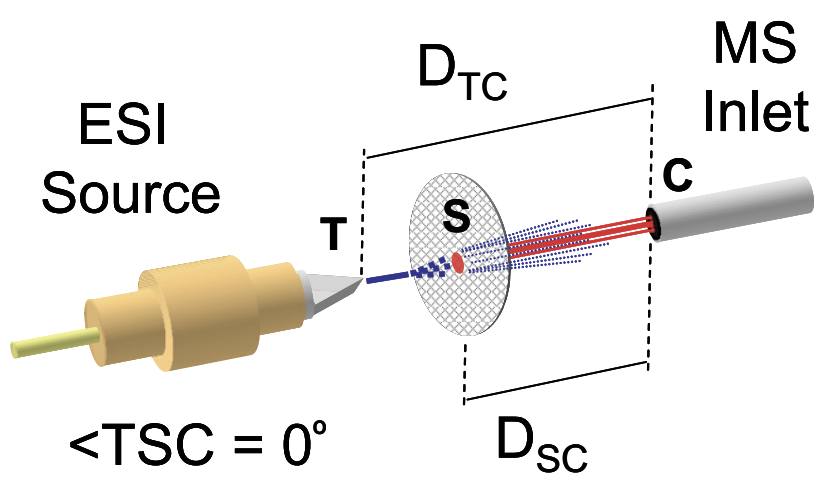

Figure 1. Transmission mode desorption electrospray ionization (TM-DESI) geometry. Sample (S) is deposited on a mesh screen and analyzed by passing an electrospray through it. The angle between the electrospray tip (T), sample (S), and capillary inlet (C) to the mass spectrometer is set to $0^{\circ} . D_{\mathrm{TC}}$ is the distance from the electrospray tip to the capillary and $D_{\mathrm{SC}}$ is the distance from the sample to the capillary.
Table 1. Sample mesh characteristics

\begin{tabular}{lccc}
\hline Mesh material & $\begin{array}{c}\text { Open } \\
\text { space }(\mu \mathrm{m})\end{array}$ & $\begin{array}{c}\text { Strand } \\
\text { diameter }(\mu \mathrm{m})\end{array}$ & $\begin{array}{c}\text { Transmittance } \\
(\%)^{\text {a }}\end{array}$ \\
\hline \hline PEEK & 300 & 200 & 36.0 \\
Nylon & 350 & 240 & 35.0 \\
Polyester & 350 & 250 & 34.0 \\
Polypropylene & 297 & 215 & 33.5 \\
Stainless steel & 381 & 250 & 36.0 \\
\hline
\end{tabular}

aThe percent transmittance was calculated as the square of the open space divided by the square of the sum of the open space and strand diameter.

anol, hexane, or acetonitrile) obtained from Fisher Scientific (Hampton, NH). Red and blue permanent markers (Fine Sharpie; Sanford Corp., Oak Brook, IL) were also used as sources of the easily ionized dyes rhodamine $6 \mathrm{G}$ and Basic Blue 7.

Five different sheets of mesh material with similar characteristics (Table 1) were purchased from Small Parts Inc. (Miramar, FL) and cut into $5 \mathrm{~mm} \times 10 \mathrm{~mm}$ rectangular pieces. Mesh pieces were rinsed with a mixture of water, methanol, and acetone and allowed to dry before use. Blank measurements were taken before sample preparation to ensure that the pieces were free of analyte or any detectable chemical interference.

\section{Mass Spectrometry}

An Omni Spray ion source (Prosolia, Inc., Indianapolis, IN) was mounted to a Thermo Fisher Scientific LTQ XL mass spectrometer (Thermo Fisher Scientific Inc., Waltham, MA) and modified to allow a $0^{\circ}$ angle between the electrospray tip and capillary inlet to the mass spectrometer. Samples were affixed to the sample slide arm of the Omni Spray ion source using a sample holder constructed of two rectangular pieces of high density polyethylene (HDPE) that held the sample screen on one end. Mass spectra were acquired by scrolling the sample mesh perpendicularly into the electrospray plume between the spray tip and the capillary inlet, thereby allowing transmission of the ionizing spray through the mesh. Specific studies (summarized in the text and discussed in further detail in the Supplementary Material, which can be found in the electronic version of this article) were carried out to determine the optimum position of the sample mesh and electrospray tip relative to the capillary inlet to the mass spectrometer.

Mass spectra were acquired in either positive or negative mode, depending on the ionization affinity of the sample, with the ion accumulation time set to $10 \mathrm{~ms}$ and signal averaging set for 4 microscans. The temperature of the heated capillary was held at $250{ }^{\circ} \mathrm{C}$ for all sample analysis. Nitrogen was used as the DESI nebulizing gas. A syringe pump (Harvard Apparatus, Holliston, MA) was used to deliver water; methanol; acetonitrile; a 50:50 (vol:vol) mixture of water and methanol; or a 50:50:0.05 (vol:vol:vol) mixture of water, 
methanol, and formic acid as the electrospray solvent. Specific studies (summarized in the text and discussed in more detail in the Supplementary material) were carried out to determine the appropriate range of nitrogen pressures, electrospray solvent flow rates, and electrospray voltages.

\section{Sample Preparation}

Depending on the experiment, samples were prepared either by spotting $1 \mu \mathrm{L}$ of solution onto a sample mesh using a $5 \mu \mathrm{L}$ syringe (SGE, Austin, TX) or by immersing the mesh in solution for several seconds. Specific studies (discussed in detail in the text) were carried out to assess the impact of the sample deposition solvent, the sample substrate, and the drying time (i.e., wet versus dry analysis).

\section{Results and Discussion}

Transmission mode desorption electrospray ionization depends on 10 experimental variables that may be subdivided into three categories: those that define the geometry of the experiment, those that characterize the electrospray, and those that govern the desorption/ ionization chemistry at the sample surface.

\section{Geometric Variables}

With a fixed electrospray angle of $0^{\circ}$ (Figure 1 ), the geometric variables of the experiment are reduced from seven [37] to two: the distance between the sample mesh and the capillary inlet to the mass spectrometer, $\mathrm{D}_{\mathrm{SC}}$, and the distance between the electrospray tip and the capillary inlet, $\mathrm{D}_{\mathrm{TC}}$. Defining these two distances necessarily dictates the position of the electrospray tip relative to the sample mesh.

Experiments using rhodamine $6 \mathrm{G}$ and Basic Blue 7 were conducted to determine the optimal range for the geometric variables $D_{\mathrm{SC}}$ and $D_{\mathrm{TC}}$. With the solvent flow rate set to $10 \mu \mathrm{L} / \mathrm{min}$ and the nebulizing gas pressure set to $100 \mathrm{psi}, D_{\mathrm{SC}}$ and $D_{\mathrm{TC}}$ were varied incrementally throughout their possible range (i.e., $5 \mathrm{~mm}<D_{\mathrm{TC}}<21$ $\mathrm{mm}$ and $1 \mathrm{~mm}<D_{\mathrm{SC}}<20 \mathrm{~mm}$ ) and an average peak area for the protonated species at each position was used to construct a contour plot of the response (see Supplementary material, Figure S1). Under these electrospray conditions, the largest responses were observed when the sample mesh was placed between 8 and $10 \mathrm{~mm}$ from the capillary inlet and the electrospray tip was held 2 to $3 \mathrm{~mm}$ from the mesh (i.e., $D_{\text {TC }}$ between 10 and $12 \mathrm{~mm}$ ) These findings correlate with what is already known about the optimal distance between an electrospray tip and a capillary inlet in a standard ESI experiment [47] and the distance between the ESI tip and a sample surface in a DESI experiment [5]. Furthermore, additional experiments conducted at lower flow rates (e.g., $3 \mu \mathrm{L} / \mathrm{min}$ ) favored $D_{\mathrm{SC}}$ values of less than 8 $\mathrm{mm}$, thereby indicating that a more compact geometry that is similar to traditional DESI may also be appropriate for TM-DESI analysis of dried residues. However, when extended to the analysis of wet samples, the response was lower at these shorter distances, a result most likely due to the incomplete desolvation of the analyte ions. Finally, the experimental results also illustrate that the TM-DESI technique is only moderately sensitive to variations in these distances under given electrospray conditions, and that slight differences in sample placement are unlikely to result in major fluctuations in signal intensities.

\section{Electrospray Variables}

Variables that characterize the electrospray in TM-DESI are identical to those in standard electrospray experiments, namely the electrospray voltage, the pressure or flow rate of the nebulizing gas, and the flow rate of the sample (i.e., the flow rate of the spray solvent). Experiments using rhodamine $6 \mathrm{G}$ and Basic Blue 7 were conducted to determine the impact of varying these variables on the TM-DESI response. With the geometry set at $D_{\mathrm{SC}}$ equal to $8 \mathrm{~mm}$ and $D_{\mathrm{TC}}$ equal to $10 \mathrm{~mm}$, the maximum average peak area was observed when the solvent flow was $10 \mu \mathrm{L} / \mathrm{min}$ and the nitrogen pressure was 100 psi, although other pairings also produced strong responses (see Supplementary material, Figure S2). Variation of the electrospray voltage showed a maximum response at $4.0 \mathrm{kV}$, with a range of values greater than $3.0 \mathrm{kV}$ providing adequate response (see Supplementary material, Figure S3). While the results for nebulizing gas pressure and electrospray voltages are typical for both standard electrospray experiments and DESI analyses [5], the optimal flow rate of 10 $\mu \mathrm{L} / \mathrm{min}$ concurred with several values reported for DESI $[7,17]$, but was higher than others performed with lower flow rates of only $2-5 \mu \mathrm{L} / \mathrm{min}[5,12]$. As discussed in the previous section, this optimal flow rate is likely an artifact of the chosen geometry and would be reduced if the geometry were more compact.

\section{Surface Desorption/Ionization Variables}

Variables that influence the surface ionization in TMDESI include the identity of the spray solvent, the identity of the sample deposition solvent, the composition and physical characteristics of the substrate material, the identity of the target analyte, and the surface density of the target analyte deposited on the substrate. The chemistry of the desorption/ionization mechanism has been the subject of several reports [12, 21, 23, 37]. TM-DESI depends on four variables that are in common with traditional DESI: the composition of the substrate material, the identity of the electrospray solvent, the identity of the target molecule, and the surface density of the target molecules on the substrate. Since TM-DESI of liquid samples is also possible, the identity of the sample deposition solvent is an additional variable that may directly influence the desorption and ionization in 


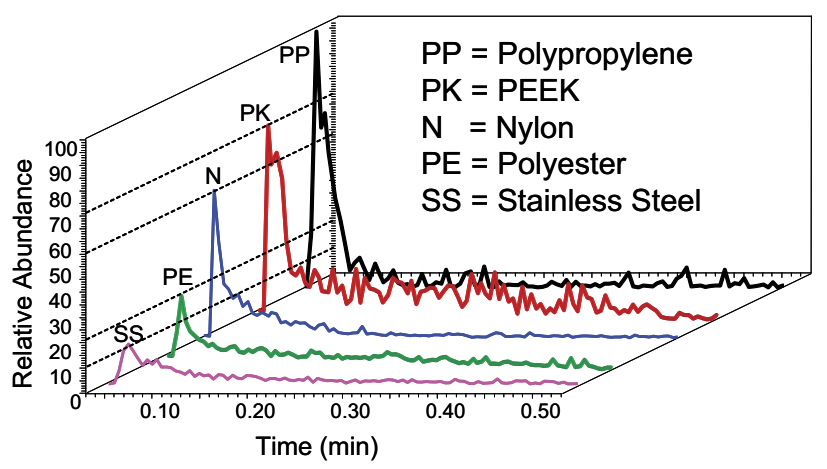

Figure 2. Relative TM-DESI signal of $10 \mathrm{pg}$ of rhodamine 6G from five different mesh materials with similar transmission characteristics (i.e., strand diameters of $\sim 200-250 \mu \mathrm{m}$ and open space of $\sim 300-400 \mu \mathrm{m})$. Samples were spotted using $1 \mu \mathrm{L}$ of methanol and allowed to dry prior to analysis. No additional potential was applied to the surfaces during the analysis.

these analyses. While a complete investigation of surface parameters was outside the scope of this work, exploratory studies were performed to investigate the potential influence of several of the principal variables.

\section{Sample Substrate}

Several attributes of the sample substrate, including the material of construction, the mesh stand size, and mesh open space (i.e., the mesh transmittance), govern how efficiently analytes are suspended on and removed from the surface. Five sample meshes of differing materials but with similar physical characteristics were investigated in this work (Table 1). As an initial study, the effect of the substrate material on the lifetime of the TM-DESI signal was investigated for rhodamine 6G, nicotine, and bradykinin at both low and high concentrations and for both wet (i.e., solvated) and dry analysis (i.e., analysis after evaporation of the deposition solvent).

As exemplified in Figure 2 for rhodamine 6G, the substrate material had a noticeable impact on the response, especially at lower concentrations. In this case the polypropylene, PEEK, and nylon meshes produced the largest responses while the polyester and stainless steel meshes produced much lower responses. It should be noted that no additional potential was applied to the surfaces during analysis. Therefore, the relatively poor ionization efficiency for the stainless steel mesh may be caused by charge dispersion at the conductive surface. For all of the compounds studied, both wet and dry analysis of low concentration samples produced sharp initial peaks, as observed in Figure 2, followed by rapid signal decay. When the concentration was increased, a sharp initial peak was still observed, but decay was at a much slower rate. In general, results obtained for nicotine and bradykinin were comparable to those for rhodamine $6 \mathrm{G}$ and look very similar to what has been previously reported for other dyes by DESI [25].

Aside from the differences observed between the mesh materials, a discrepancy was also noted between wet and dry analysis of samples at higher concentrations. In this case, the signal decay for dry analysis was much more gradual as analyte was continually desorbed from the surface. In contrast, the wet analysis produced slightly larger but more rapidly decaying responses since the analyte was already solvated and thus easier to desorb from the surface. Overall, these results suggest that the identity of the surface substrate may influence the performance of TM-DESI. Therefore, additional studies that more comprehensively evaluate the performance of a larger variety of meshes are underway.

\section{Electrospray Solvent}

The importance of the electrospray solvent composition on DESI analysis has been reported numerous times [5, 12]. These studies have suggested that the optimum solvent is analyte dependent and that the efficacy of a particular solvent is a function of its polarity and the solubility of the target analyte. Various common electrospray solvents including methanol, water, acetonitrile, and mixtures of these solvents have been utilized in DESI analyses [5]. In the present study, experiments were undertaken to study the effect of varying the electrospray solvent on the response of nicotine and bradykinin. In each case, $1 \mu \mathrm{L}$ of solution $(1 \mathrm{ng} / \mu \mathrm{L}$ of nicotine in methanol or $50 \mu \mathrm{M}$ bradykinin in methanol) was deposited onto a nylon mesh and allowed to dry completely before analysis.

Table 2 summarizes the results for these experiments and confirms that electrospray solvent effects are also observed in the transmission mode. The largest response for nicotine was observed when methanol was used as the spray solvent, while much lower responses were observed using water or acetonitrile. In contrast, the results for bradykinin show that the largest response was observed when water was the spray solvent and much lower responses were observed for either pure methanol or pure acetonitrile. Thus, the optimum spray solvent depended on the identity of the target analyte. These results again illustrate that the mechanism of desorption in the transmission mode is likely similar to traditional DESI when the deposition solvent is allowed to evaporate completely before analysis.

Table 2. Relative percent responses of dried nicotine and bradykinin samples using various electrospray solvents ${ }^{\mathrm{a}}$

\begin{tabular}{lccrc}
\hline \multicolumn{1}{c}{ Analyte } & Methanol & $\begin{array}{c}\text { Methanol/ } \\
\text { water }^{\mathrm{b}}\end{array}$ & Water & Acetonitrile \\
\hline \hline Nicotine & 100.0 & 60.0 & 25.8 & 21.8 \\
Bradykinin & 10.7 & 82.2 & 100.0 & 4.2 \\
\hline
\end{tabular}

${ }^{\text {a }}$ The relative percent response was calculated as the average response from 10 replicate sample preparations divided by the maximum average response. All samples were prepared on a nylon mesh. bThe ratio of methanol to water was 1:1 by volume. 


\section{Deposition Solvent}

The electrospray angle in most DESI experiments is typically much greater than zero (i.e., $40^{\circ}$ to $70^{\circ}$ ), which causes rapid erosion of liquids from uniform sample surfaces such as glass, plastics, and metal. Thus, analysis of liquids in traditional DESI is most successful from rough substrates such as paper or TLC plates that absorb the solvent and hold the liquid analytes in place. The $0^{\circ}$ electrospray in TM-DESI eliminates this erosion effect as the nebulizing gas, desolvated ions, and unionized droplets are directed through the surface at an angle perpendicular to it, thereby reducing the tendency for surface resolvation and spreading of the target analyte on the substrate. Therefore, analysis of liquids from smooth mesh surfaces is possible in TM-DESI and, as a consequence, the deposition solvent plays a more prominent role in the surface chemistry of the analysis.

To investigate the impact of the deposition solvent, the experiments conducted to test the impact of the electrospray solvent were repeated using various deposition solvents. However, unlike the previous experiments, the samples were analyzed while they were suspended as liquid droplets in the mesh, not dried to a solid film. Table 3 summarizes the results obtained for nicotine using three electrospray solvents (i.e., methanol, acetonitrile, water) and four deposition solvents (i.e., methanol, acetonitrile, water, hexane). The most compelling results are the differences observed amongst a set of analyses that utilized the same electrospray solvent, but differing deposition solvents. For example, relative responses varied between $22.8 \%$ and $100 \%$ when the deposition solvent was varied and methanol was used as the electrospray solvent.

Table 4 summarizes the results obtained for bradykinin using four electrospray solvents (i.e., methanol, acetonitrile, water, methanol/water) and two deposition solvents (i.e., methanol, water). These results correlate well with those presented in Table 2 and also suggest that the efficiency of ionization may be controlled by either the electrospray solvent or the deposition solvent. More specifically, from Table 2, the largest responses for bradykinin (as a dried film) were observed when either water or a mixture of water and methanol was used as the electrospray solvent. Table 4 also shows that the largest responses for solvated brady-

Table 3. Relative percent responses of wet nicotine samples using various electrospray and deposition solvents ${ }^{\mathrm{a}}$

\begin{tabular}{lccr}
\hline & \multicolumn{3}{c}{ Electrospray solvent } \\
\cline { 2 - 4 } Deposition solvent & Methanol & Acetonitrile & Water \\
\hline \hline Methanol & 100.0 & 37.7 & 36.6 \\
Acetonitrile & 83.9 & 34.0 & 22.7 \\
Water & 22.8 & 10.2 & 11.5 \\
Hexane & 59.6 & 14.6 & 4.9 \\
\hline
\end{tabular}

${ }^{a}$ The relative percent response was calculated as the average response from 10 replicate sample preparations divided by the maximum average response. All samples were prepared on a nylon mesh.
Table 4. Relative percent responses of wet bradykinin samples using various electrospray and deposition solvents ${ }^{\mathrm{a}}$

\begin{tabular}{lcccc}
\hline & \multicolumn{4}{c}{ Electrospray solvent } \\
\cline { 2 - 5 } $\begin{array}{c}\text { Deposition } \\
\text { solvent }\end{array}$ & Methanol & $\begin{array}{c}\text { Methanol/ } \\
\text { water }^{\text {a }}\end{array}$ & Water & Acetonitrile \\
\hline \hline Methanol & 23.3 & 80.8 & 96.9 & 13.2 \\
Water & 100.0 & 64.5 & 42.0 & 44.6 \\
\hline
\end{tabular}

${ }^{a}$ The relative percent response was calculated as the average response from 10 replicate sample preparations divided by the maximum average response. All samples were prepared on a nylon mesh.

kinin were observed when water was present, either as the deposition solvent in combination with a methanolic electrospray or as the electrospray solvent in combination with a methanolic deposition. Interestingly, the average responses for either the all-methanol or all-water systems were far lower. Furthermore, the magnitude of the response observed when a mixture of methanol and water was used as the electrospray solvent was between that observed for the pure solvent systems.

These results clearly illustrate that the identity of the deposition solvent has an impact on the response in TM-DESI and that the mechanism in the solvated transmission mode analysis is dependent not only on the surface, analyte, and ionizing solvent, but also on the solvent that suspends the target analyte on the mesh. Elucidation of the ionization mechanism must therefore consider not only the interaction of the electrospray solvent with the analyte, but also the interaction of the deposition solvent with the surface and electrospray solvent, the partitioning of the analyte between the deposition solvent and the surface, and the possible partitioning of the analyte between the two solvents.

One possible mechanism could assume that there is no adsorption of the target analyte to the surface and that the ionization results from a partitioning of the analyte between the two solvents. This mechanism would be similar to a liquid-liquid extraction where the miscibility of the two solvents and the corresponding solubility of the target analyte have a large influence on the eventual efficacy of the ionization. Results presented in Table 3 for the analysis of nicotine when hexane was used as the deposition solvent and water was used as the electrospray solvent support this argument. Since the miscibility of these two solvents is minimal, the analyte would have less opportunity to partition into the electrospray solvent and therefore little tendency to be ionized.

Another possible mechanism could involve a "secondary" electrospray of a completely suspended analyte where a suspended analyte droplet is dislodged from the surface by the electrospray plume and subsequently ionized by the desolvation of the analyte amidst the other electrospray solvent ions. Finally, like traditional DESI, the mechanism could involve a droplet pickup mechanism in which the analyte is picked up from the surface or from a thin layer of solvent sur- 
Table 5. Figures of merit ${ }^{\mathrm{a}}$

\begin{tabular}{lccc}
\hline \multicolumn{1}{c}{ Analyte } & LOD (dry) pg & $\begin{array}{c}\text { LOD (wet) pg/ } \\
\mu \mathrm{L}\end{array}$ & \% RSD (wet) \\
\hline \hline Nicotine $^{\mathrm{b}}$ & 1.0 & 0.5 & 11.4 \\
Bradykinin $^{\mathrm{c}}$ & 0.3 & 0.3 & 9.6 \\
\hline
\end{tabular}

${ }^{a}$ All analyses were performed using a PEEK mesh and a deposition volume of $1 \mu \mathrm{L}$ (methanol).

bMethanol was used as the spray solvent.

${ }^{\mathrm{c}} \mathrm{A}$ mixture of water, methanol, and formic acid (50:50:0.05\% by volume) was used as the spray solvent.

${ }^{\mathrm{d}}$ Result of 10 replicate measurements taken at a concentration 10 times the limit of detection (LOD).

rounding the surface $[5,21,23]$. However, in this case the surface activity of the solute in the various deposition solvents would also be a factor as analytes that favored the surface over the solvent would more likely be available for "pickup" by the electrospray solvent. The data presented here are not sufficient to conclusively elucidate the mechanism of the solvated transmission mode desorption ionization, but they will serve as a guide for subsequent investigations.

\section{Figures of Merit}

Table 5 summarizes the detection limit results for nicotine and bradykinin by TM-DESI. Comparison of the results for wet and dry analyses does not suggest a clear benefit in sensitivity using either method. However, it is worth noting that TM-DESI analysis of wet samples consumes the sample more rapidly than dry analysis, since the release of the suspended solvent droplets is nearly instantaneous when the sample intersects the nebulizing plume. Therefore, samples deposited as $1 \mu \mathrm{L}$ or less and analyzed wet have a "spot" size on the same order as the DESI spray. In contrast, TM-DESI of dry samples produces longerlived signals because the desorption process must be initiated by resolvation of analytes that have dried on the mesh. In this case, the entire "spot" may not be sampled simultaneously. Therefore, the relative similarity in the sensitivity of the wet and dry analyses may be a balance between these factors. While the reported detection limits cannot necessarily be extended to all analyses, they do suggest that the transmission mode sensitivity is comparable with that of traditional DESI for small molecules like nicotine and peptides such as bradykinin [5].

The qualitative repeatability of TM-DESI was tested by performing 50 replicate analyses of wet and dry samples of both bradykinin and nicotine at sample concentrations twice the limit of detection. For the nicotine samples, nicotine was detected in all 50 samples, and for the bradykinin samples, 49 of 50 samples yielded positive results. In addition, the quantitative reproducibility at concentrations 10 times the limit of detection was also investigated (Table 5). The results show $\sim 10 \%$ to $12 \%$ RSD for the analysis of wet samples deposited as $1 \mu \mathrm{L}$ in methanol. These results are prom- ising for qualitative screening, but quantitative analyses may require even better precision.

The possibility of using a codeposited internal standard for TM-DESI analysis of liquid samples was explored. In this study, nicotine $(10 \mathrm{pg} / \mu \mathrm{L})$ was added as an internal standard to cotinine standards (50-500 $\mathrm{pg} / \mu \mathrm{L}$ ) in methanol and analyzed immediately following deposition of $1 \mu \mathrm{L}$ of sample on a PEEK mesh. Five replicate measurements were taken at four concentrations of cotinine, and the resulting calibration curve is shown in Figure 3. The percent RSD for the individual points was reduced from an average of $16 \%$ without the internal standard to an average of $6.7 \%$ with it. These results are encouraging and suggest that further work should be done to improve the performance. Moreover, results recently reported by Ifa et al. describe similar success and suggest that further improvements may also come from using a deuterated internal standard [38]. Additionally, monitoring of selected transitions in MS-MS analyses or competitive reactions using reactive DESI may also help facilitate better quantitative capability.

\section{Applications}

Mass spectra collected for mixtures of peptides and flavonoids obtained via a high throughput adaptation of the TM-DESI analysis are depicted in Figure $4 \mathrm{a}$ and $\mathrm{b}$. These spectra were acquired using an alternate sampling approach in which the mesh was simply immersed in the sample solution for $1 \mathrm{~s}$, affixed to the sample holder, and scrolled into the electrospray plume. This methodology eliminated precise sample spotting and therefore reduced the sample preparation time. The efficiency was thus greatly increased, and sample analysis, including preparation, was routinely performed in less than $20 \mathrm{~s}$. This high speed qualitative screening technique could find applications where sample volumes are

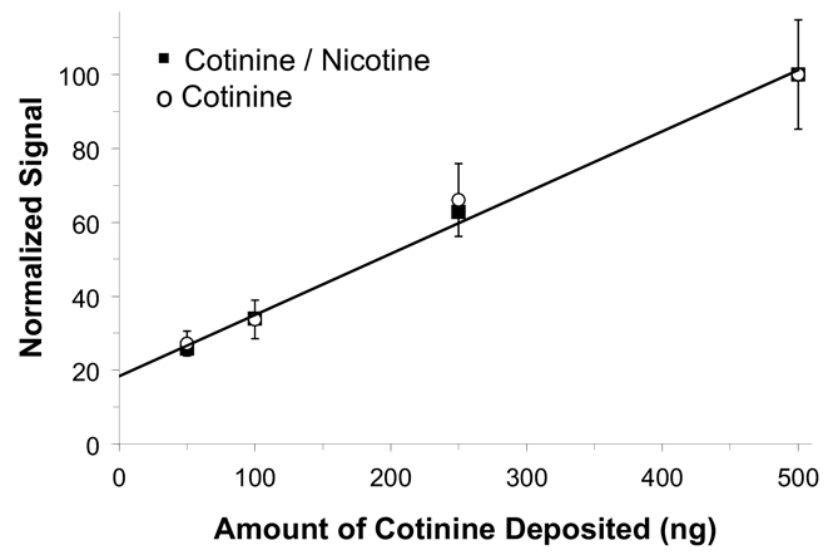

Figure 3. Calibration curve for cotinine with and without the use of nicotine as an internal standard. Error bars indicate one standard deviation of five replicate measurements of cotinine without adjustment to the internal standard. 

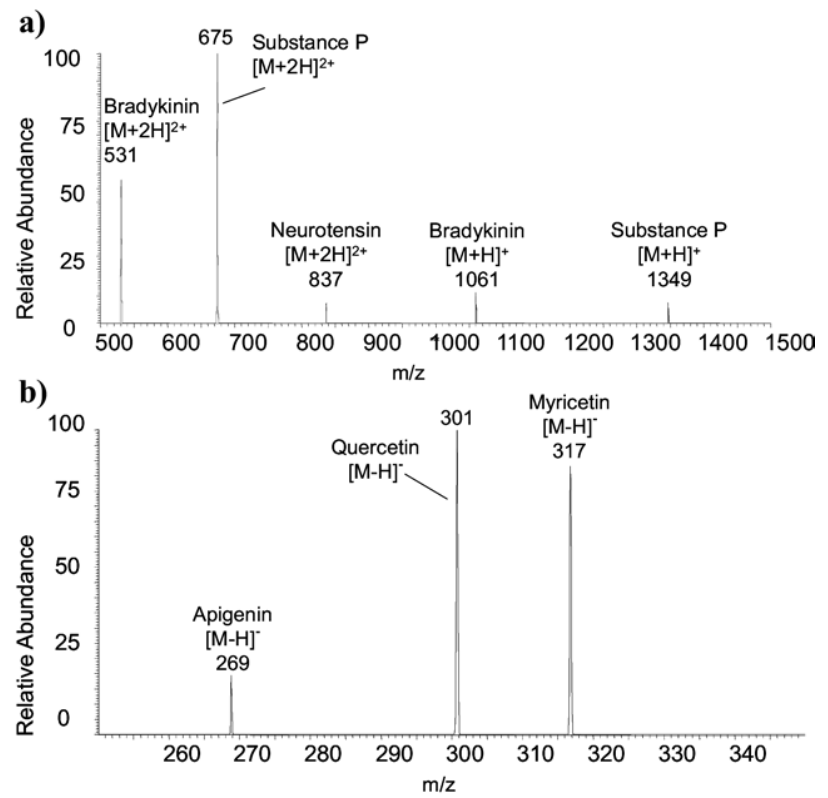

Figure 4. TM-DESI mass spectra for mixtures of (a) bradykinin, neurotension, and substance $\mathrm{P}(1 \mu \mathrm{M}$ in methanol) and (b) apigenin, quercetin, and myricetin $(100 \mu \mathrm{g} / \mathrm{mL}$ in methanol). Analysis was performed by immersing the mesh in the solution, affixing the mesh to the source, and scrolling the wet mesh into the electrospray plume.

not the limiting factor and quantitative analysis of the solution is not the primary objective.

One potential application of TM-DESI is the analysis of foreign substances and their metabolites in biological matrices (e.g., urine, plasma, saliva). As an example, TM-DESI was used to analyze urine samples for cotinine, the primary urinary metabolite of nicotine. Here, fresh urine samples were collected and spiked with cotinine at a concentration of $100 \mathrm{pg} / \mu \mathrm{L}$. Samples were spotted $(1 \mu \mathrm{L})$ either directly onto a PEEK mesh and dried before analysis or diluted 1:100 with methanol and analyzed wet. Similar dilutions or sample extractions have been utilized in some [28], but not all [30, 39], DESI studies involving urine. In the present study, direct analysis of the liquid urine samples without this dilution showed significant ion suppression by the urine matrix, presumably due to the remaining solvated salts. TM-DESI of dried urine samples showed less ion suppression. These results are in accordance with published reports highlighting the high salt tolerance of typical DESI experiments [36], and point toward an ESI-like component in the ionization mechanism of liquid samples via TM-DESI.

Figure 5a depicts a representative mass spectra obtained in the analysis. The ion of $m / z 177$ corresponds to protonated cotinine, whereas the ion of $\mathrm{m} / \mathrm{z} 199$ corresponds to sodium-cationized cotinine. A MS-MS spectrum of the ion of $\mathrm{m} / \mathrm{z} 177$ was collected to confirm the presence of cotinine (Figure $5 \mathrm{~b}$ ). The major product ion $(\mathrm{m} / \mathrm{z} 146)$ corresponds to the loss of $\mathrm{CH}_{3} \mathrm{NH}_{2}$. The ions of $\mathrm{m} / \mathrm{z} 98$ and 80 stem from cleavage of the bond between the pyridine and pyrrolidine rings. The resulting product ion spectrum matches previously reported results for analysis of cotinine by LC-MS $[48,49]$ and illustrates that tandem mass spectrometry is also possible in TM-DESI analysis of wet samples, despite the relatively short-lived ion signal. Furthermore, the diluted concentration of $1 \mathrm{pg} / \mu \mathrm{L}$ in this analysis is above the detection limit of $0.156 \mathrm{pg} / \mu \mathrm{L}$ reported by LC-ESIMS, but in the vicinity of the limit of quantitation (2.5 $\mathrm{pg} / \mu \mathrm{L})$ reported in the same study [48]. While TMDESI did not produce a lower detection limit than LC-MS, the analysis was performed in seconds compared to the several minutes required for the LC-MS assay.

\section{Conclusions}

The results reported here demonstrate that TM-DESI is capable of producing high quality mass spectral data for both solid residues and liquid samples in very short periods of time. The $0^{\circ}$ electrospray angle transmits the ionizing plume through the sample surface and effectively reduces the number of geometric experimental variables to two, thus providing a useful simplification to the traditional DESI experiment. The bulk of the variability in the TM-DESI analysis remains defined by the five variables that describe the desorption process: the electrospray solvent, the deposition solvent, the substrate material, the target analyte, and the partition-
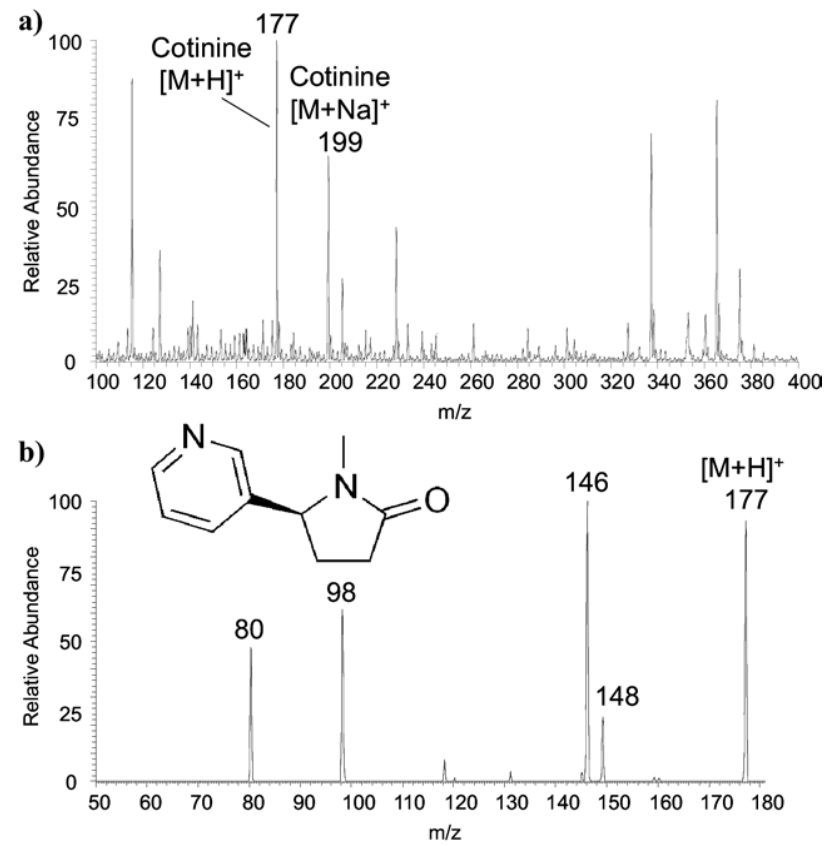

Figure 5. TM-DESI spectrum of (a) urine containing cotinine, the primary urinary metabolite of nicotine, and (b) MS-MS spectrum of the ion of $\mathrm{m} / \mathrm{z} 177$ used to confirm the presence of the protonated cotinine species. The major product ion was of $\mathrm{m} / \mathrm{z} 146$, which is the loss of $\mathrm{CH}_{3} \mathrm{NH}_{2}$ from cotinine. The ions of $\mathrm{m} / \mathrm{z} 98$ and 80 stem from cleavage of the bond between the pyridine and pyrrolidine rings. 
ing of that analyte onto the substrate or into the deposition solvent. Ongoing research aims to move beyond the simple surfaces and solvents tested here and, in doing so, improve the selectivity of the TM-DESI technique by taking advantage of the unique chemistries that can exist in these multicomponent systems.

\section{Acknowledgments}

The authors gratefully acknowledge funding from the Welch Foundation (F1155) and the National Science Foundation (CHE0718320). Additional recognition is also due to Signature Science, LLC for use of the Omni Spray ionization source.

\section{Appendix A. Supplementary Material}

Supplementary material associated with this article may be found in the online version at doi:10.1016/ j.jasms.2008.07.002.

\section{References}

1. Takats, Z.; Wiseman, J. M.; Gologan, B.; Cooks, R. G. Mass Spectrometry Sampling Under Ambient Conditions with Desorption Electrospray Ionization. Science 2004, 306, 471-473.

2. Chen, H.; Talaty, N.; Takats, Z.; Cooks, R. G. Desorption Electrospray Ionization Mass Spectrometry for High-Throughput Analysis of Pharmaceutical Samples in the Ambient Environment. Anal. Chem. 2005, 77, 6915-6927.

3. Cotte-Rodriguez, I.; Takats, Z.; Talaty, N.; Chen, H.; Cooks, R. G. Desorption Electrospray Ionization of Explosives on Surfaces: Sensitivity and Selectivity Enhancement by Reactive Desorption Electrospray Ionization. Anal. Chem. 2005, 77, 6755-6764.

4. Takats, Z.; Cotte-Rodriguez, I.; Talaty, N.; Chen, H.; Cooks, R. G. Direct Trace Level Detection of Explosives on Ambient Surfaces by Desorption Electrospray Ionization Mass Spectrometry. Chem. Comm. 2005, 1950-1952.

5. Takats, Z.; Wiseman, J. M.; Cooks, R. G. Ambient Mass Spectrometry Using Desorption Electrospray Ionization (DESI): Instrumentation, Mechanisms, and Applications in Forensics, Chemistry, and Biology. J. Mass Spectrom. 2005, 40, 1261-1275.

6. Talaty, N.; Takats, Z.; Cooks, R. G. Rapid in Situ Detection of Alkaloids in Plant Tissue Under Ambient Conditions using Desorption Electrospray Ionization. Analyst 2005, 130, 1624-1633.

7. Van Berkel, G. J.; Ford, M. J.; Deibel, M. A. Thin-Layer Chromatography and Mass Spectrometry Coupled Using Desorption Electrospray Ionization. Anal. Chem. 2005, 77, 1207-1215.

8. Weston, D. I.; Bateman, R.; Wilson, I. D.; Wood, T. R.; Creaser, C. S Direct Analysis of Pharmaceutical Drug Formulations Using Ion Mobility Spectrometry/Quadrupole-Time-of-Flight Mass Spectrometry Combined with Desorption Electrospray Ionization. Anal. Chem. 2005, $77,7752-7580$

9. Williams, J. P.; Scrivens, J. H. Rapid Accurate Mass Desorption Electrospray Ionization Tandem Mass Spectrometry of Pharmaceutical Samples. Rapid Commun. Mass Spectrom. 2005, 19, 3643-3650.

10. Bereman, M. S.; Nyadong, L.; Fernandez, F. M.; Muddiman, D. C. Direct High-Resolution Peptide and Protein Analysis by Desorption Electrospray Ionization Fourier Transform Ion Cyclotron Resonance Mass Spectrometry. Rapid Commun. Mass Spectrom. 2006, 20, 3409-3411.

11. Chen, H.; Zhengzheng, P.; Talaty, N.; Raftery, D.; Cooks, R. G. Combining Desorption Electrospray Ionization Mass Spectrometry and Nuclear Magnetic Resonance for Differential Metabolomics without Sample Preparation. Rapid Commun. Mass Spectrom. 2006, 20, 1577-1584.

12. Cooks, R. G.; Ouyang, Z.; Takats, Z.; Wiseman, J. M. Ambient Mass Spectrometry. Science 2006, 311, 1566-1569.

13. Cotte-Rodriguez, I.; Cooks, R. G. Nonproximate Detection of Explosives and Chemical Warfare Agent Stimulants by Desorption Electrospray Ionization Mass Spectrometry. Chem. Commun. 2006, 2968-2970.

14. D'Agostino, P. A.; Hancock, J. R.; Chenier, C. L.; Lepage, J. Liquid Chromatography Electrospray Tandem Mass Spectrometric and Desorption Electrospray Ionization Tandem Mass Spectrometric Analysis of Chemical Warfare Agents in Office Media Typically Collected During a Forensic Investigation. J. Chromatogr. A 2006, 1110, 86-94.

15. Hu, Q.; Talaty, N.; Noll, R. J.; Cooks, R. G. Desorption Electrospray Ionization Using an Orbitrap Mass Spectrometer: Exact Mass Measurements on Drugs and Peptides. Rapid Commun. Mass Spectrom. 2006, 20, 3403-3408.
16. Jackson, A. T.; Williams, J. P.; Scrivens, J. H. Desorption Electrospray Ionization Mass Spectrometry and Tandem Mass Spectrometry of Low Molecular Weight Synthetic Polymers. Rapid Commun. Mass Spectrom. 2006, 20, 2717-2727.

17. Kauppila, T. J.; Talaty, N.; Salo, P. K.; Kotiaho, T.; Kostiainen, R.; Cooks, R. G. New Surfaces for Desorption Electrospray Ionization Mass Spectrometry: Porous Silicon and Ultra-Thin Layer Chromatography Plates. Rapid Commun. Mass Spectrom. 2006, 20, 2143-2150.

18. Kauppila, T. J.; Wiseman, J. M.; Ketola, R. A.; Kotiaho, T.; Cooks, R. G.; Kostiainen, R. Desorption Electrospray Ionization Mass Spectrometry for the Analysis of Pharmaceuticals and Metabolites. Rapid Commun. Mass Spectrom. 2006, 20, 387-392.

19. Mulligan, C. C.; Talaty, N.; Cooks, R. G. Desorption Electrospray Ionization with a Portable Mass Spectrometer: In Situ Analysis of Ambient Surfaces. Chem. Commun. 2006, 1709-1711.

20. Nefliu, M.; Venter, A.; Cooks, R. G. Desorption Electrospray Ionization and Electrosonic Spray Ionization for Solid- and Solution-Phase Analysis of Industrial Polymers. Chem. Commun. 2006, 888-890.

21. Venter, A.; Sojka, P. E.; Cooks, R. G. Droplet Dynamics and Ionization Mechanisms in Desorption Electrospray Ionization Mass Spectrometry. Anal. Chem. 2006, 78, 8549-8555.

22. Williams, J. P.; Patel, V. J.; Holland, R.; Scrivens, J. H. The Use of Recently Described Ionization Techniques for the Rapid Analysis of Some Common Drugs and Samples of Biological Origin. Rapid Commun. Mass Spectrom. 2006, 20, 1447-1456.

23. Costa, A. B.; Cooks, R. G. Simulation of Atmospheric Transport and Droplet-Thin Film Collisions in Desorption Electrospray Ionization. Chem. Commun. 2007, 3915-3917.

24. D'Agostino, P. A.; Chenier, C. L.; Hancock, J. R.; Lepage, J. Desorption Electrospray Ionization Mass Spectrometric Analysis of Chemical Warfare Agents from Solid-Phase Microextraction Fibers. Rapid Commun. Mass Spectrom. 2007, 21, 543-549.

25. Ifa, D. R.; Gumaelius, L. M.; Eberlin, L. S.; Manicke, N. E.; Cooks, R. G. Forensic Analysis of Inks by Imaging Desorption Electrospray Ionization (DESI) Mass Spectrometry. Analyst 2007, 132, 461-467.

26. Ifa, D. R.; Wiseman, J. M.; Qingyu, S.; Cooks, R. G. Development of Capabilities for Imaging Mass Spectrometry Under Ambient Conditions with Desorption Electrospray Ionization (DESI). Int. J. Mass Spectrom. 2007, 259, 8-15.

27. Justes, D. R.; Talaty, N.; Cotte-Rodriguez, I.; Cooks, R. G. Detection of Explosives on Skin Using Ambient Ionization Mass Spectrometry. Chem. Commun. 2007, 2142-2144.

28. Kauppila, T. I.; Talaty, N.; Kuuranne, T.; Kotiaho, T.; Kostiainen, R.; Cooks, R. G. Rapid Analysis of Metabolites and Drugs of Abuse from Urine Samples by Desorption Electrospray Ionization-Mass Spectrometry. Analyst 2007, 132, 868-875.

29. Nyadong, L.; Green, M. D.; De Jesus, V. R.; Newton, P. N.; Fernandez, F. M. Reactive Desorption Electrospray Ionization Linear Ion Trap Mass Spectrometry of Latest-Generation Counterfeit Antimalarials via Noncovalent Complex Formation. Anal. Chem. 2007, 79, 2150-2157.

30. Pan, Z.; Gu, H.; Talaty, N.; Chen, H.; Shanaiah, N.; Hainline, B. E.; Cooks, R. G.; Raftery, D. Principal Component Analysis of Urine Metabolites Detected by NMR and DESI-MS in Patients with Inborn Errors of Metabolism. Anal. Bioanal. Chem. 2007, 387, 539-549.

31. Ricci, C.; Nyadong, L.; Fernandez, F. M.; Newton, P. N.; Kazarian, S. G. Combined Fourier-Transform Infrared Imaging and Desorption Electrospray-Ionization Linear Ion-Trap Mass Spectrometry for Analysis of Counterfeit Antimalarial Tablets. Anal. Bioanal. Chem. 2007, 387, 551-559.

32. Shin, Y.-S.; Drolet, B.; Mayer, R.; Dolence, K.; Basile, F. Desorption Electrospray Ionization-Mass Spectrometry of Proteins. Anal. Chem. 2007, 79, 3514-3518.

33. Song, Y.; Cooks, R. G. Reactive Desorption Electrospray Ionization for Selective Detection of the Hydrolysis Products of Phosphonate Esters. J. Mass Spectrom. 2007, 42, 1086-1092.

34. Venter, A.; Cooks, R. G. Desorption Electrospray Ionization in a Small Pressure-Tight Enclosure. Anal. Chem. 2007, 79, 6398-6403.

35. Williams, J. P.; Hilton, G. R.; Thalassinos, K.; Jackson, A. T.; Scrivens, J. H. The Rapid Characterization of Poly(Ethylene Glycol) Oligomers Using Desorption Electrospray Ionization Tandem Mass Spectrometry Combined with Novel Product Ion Peak Assignment Software. Rapid Commun. Mass Spectrom. 2007, 21, 1693-1704.

36. Jackson, A. U.; Talaty, N.; Cooks, R. G.; Van Berkel, G. J. Salt Tolerance of Desorption Electrospray Ionization (DESI). J. Am. Soc. Mass Spectrom. 2007, 18, 2218-2225.

37. Nefliu, M.; Smith, J. N.; Venter, A.; Cooks, R. G. Internal Energy Distributions in Desorption Electrospray Ionization (DESI). J. Am. Soc. Mass Spectrom. 2008, 19, 420-427.

38. Ifa, D. R.; Manicke, N. E.; Rusine, A. L.; Cooks, R. G. Quantitative Analysis of Small Molecules by Desorption Electrospray Ionization Mass Spectrometry from Polytetrafluoroethylene Surfaces. Rapid Commun. Mass Spectrom. 2008, 22, 503-510.

39. Huang, G.; Chen, H.; Zhang, X.; Cooks, R. G.; Ouyang, Z. Rapid Screening of Anabolic Steroids in Urine by Reactive Desorption Electrospray Ionization. Anal. Chem. 2007, 79, 8327-8332.

40. Bereman, M. S.; Williams, T. I.; Muddiman, D. C. Carbohydrate Analysis by Desorption Electrospray Ionization Fourier Transform Ion Cyclotron Resonance Mass Spectrometry. Anal. Chem. 2007, 79, 8812 8815. 
41. Cody, R. B.; Laramee, J. A.; Durst, H. D. Versatile New Ion Source for the Analysis of Materials in Open Air under Ambient Conditions. Anal. Chem. 2005, 77, 2297-2302.

42. Song, Y.; Cooks, R. G. Atmospheric Pressure Ion/Molecule Reactions for the Selective Detection of Nitroaromatic Explosives Using Acetonitrile and Air as Reagents. Rapid Commun. Mass Spectrom. 2006, 20, 3130-3138.

43. Shiea, J.; Huang, M.; Hsu, H.; Lee, C.; Yuan, C.; Beech, I.; Sunner, J. Electrospray-Assisted Laser Desorption/Ionization Mass Spectrometry for Direct Ambient Analysis of Solids. Rapid Commun. Mass Spectrom. 2005, 19, 3701-3704.

44. McEwen, C. N.; McKay, R. G.; Larsen, B. S. Analysis of Solids, Liquids, and Biological Tissues Using Solids Probe Introduction at Atmospheric Pressure on Commercial LC/MS Instruments. Anal. Chem. 2005, 77, 7826-7831.

45. Andrade, F. J.; Shelley, J. T.; Wetzel, W. C.; Webb, M. R.; Gamez, G.; Ray, S. J.; Hieftje, G. M. Atmospheric Pressure Chemical Ionization Source. 1.
Ionization of Compounds in the Gas Phase. Anal. Chem. 2008, 80, 2646-2653.

46. Andrade, F. J.; Shelley, J. T.; Wetzel, W. C.; Webb, M. R.; Gamez, G.; Ray, S. J.; Hieftje, G. M. Atmospheric Pressure Chemical Ionization Source. 2. Ionization for the Direct Analysis of Solid Compounds. Anal. Chem. 2008, 80, 2646-2653.

47. Page, J. S.; Kelly, R. T.; Tang, K.; Smith, R. D. Ionization and Transmission Efficiency in an Electrospray Ionization-Mass Spectrometry Interface. J. Am. Soc. Mass Spectrom. 2007, 18, 1582-1590.

48. Chadwick, C. A.; Keevil, B. Measurement of Cotinine in Urine by Liquid Chromatography Tandem Mass Spectrometry. Ann. Clin. Biochem. 2007, 44, 455-462.

49. Murphy, S. E.; Villata, P.; Ho, S. W.; von Weymarn, L. B. Analysis of $\left[3^{\prime}, 3^{\prime}-\mathrm{d} 2\right]-$ Nicotine and $\left[3^{\prime}, 3^{\prime}-\mathrm{d} 2\right]-$ Cotinine by Capillary Liquid Chromatography-Electrospray Tandem Mass Spectrometry. J. Chromatogr. B 2007, 857, 1-8. 